doi: http://dx.doi.org/10.5892/ruvrv.2011.92.202214

\title{
A ATUALIDADE DO CONCEITO DE ANGÚSTIA DE KIERKEGAARD
}

\section{THE PRESENT CONCEPT OF ANGST OF KIERKEGAARD}

\author{
Pedro Carlos Ferreira SANTOS ${ }^{1}$
}

\begin{abstract}
RESUMO: A atualidade do conceito de angústia de Kierkegaard é uma tentativa de demonstrar como o filósofo dinamarquês Soren Kierkegaard soube perceber as transformações socioculturais de seu tempo. Ele foi capaz de fazer uma analise profunda da angústia que continua ainda válida para hoje a despeito dos mais de 150 anos que nos separam no tempo. A angústia do homem contemporâneo tem muito em comum com a angustia tratada por Kierkegaard nas suas obras. Daí a importância de retomarmos a leitura desse pensador neste inicio de século, ele que foi um dos pensadores importantes do existencialismo é um antecipador da nossa época.
\end{abstract}

Palavras-chave: Filosofia. Existencialismo. Angústia. Desespero. Pós modernidade.

ABSTRACT: The relevance of Kierkegaard's concept of anxiety is an attempt to demonstrate how the Danish philosopher Soren Kierkegaard learned to realize socio-cultural transformations of his time. He was able to make a profound analysis of the anguish that is still valid today in spite of more than 150 years that separate us in time. The anguish of modern man has much in common with the anxiety treated by Kierkegaard in his works. Hence the importance of resuming the reading of this early thinker in this century, he was one of the leading thinkers of existentialism is a forerunner of our time.

Key-words ${ }^{1}$ : Philosophy. Exixtentalism. Distress. Despair. Post modernity

\footnotetext{
${ }^{1}$ Mestre em Educação, Especialista em Filosofia Contemporânea e Ética. Graduação em Filosofia. Professor da Universidade Vale do Rio Verde (UninCor). E-mail: prof.pedro.santos@unincor.edu.br
} 


\section{INTRODUÇÃO}

Neste artigo tentaremos mostrar como esta análise continua atual e pertinente aos nossos dias, A angústia do homem contemporâneo está profundamente enraizada naquela angústia descrita por Kierkegaard, daí podermos concluir que dada a distância cronológica entre nós e Kierkegaard ele foi sem dúvida um antecipador da nossa época, no sentido de que foi capaz de captar problemas que se tornariam concretos para o homem só muito mais tarde.

Soren Kierkegaard nasceu na Dinamarca em 1813 teve uma vida atribulada por problemas pessoais e familiares e em um espaço de vinte anos vê a morte de dois irmãos e três irmãs e depois a própria mãe. Em meio a isto tem ainda a decepção amorosa com a noiva Regina Olsen. Assim a sua Filosofia, é fruto de seus próprios dramas existenciais. No mês de outubro de 1855, Kierkegaard sofreu uma queda na rua e foi hospitalizado, com paralisia nas pernas. Recusando-se a receber assistência religiosa, faleceu quarenta dias depois. É considerado o pai do existencialismo.

\section{O CONCEITO DE ANGÚSTIA}

A palavra angústia, em sentido mais amplo quer dizer sufoco, estado em que a pessoa se sente sufocada perante um perigo que está eminente inevitável e em parte não foi ainda experimentado, Esta angústia não tem origem externa, mas exclusivamente interna. Assim, a angústia não tem um objeto específico como o medo que se refere sempre a uma ameaça concreta da qual nós devemos nos prevenir.

A partir de Kierkegaard o tema da angústia assume uma importância central dentro da filosofia, sobretudo para a corrente existencialista, da qual ele é considerado o iniciador, A angústia está ligada ao nada, ao vazio. Neste estado o sujeito é pura possibilidade, ainda não está determinado.

Segundo Kierkegaard a angústia é a vertigem da liberdade. $\mathrm{O}$ indivíduo sente ao mesmo tempo uma repulsa e uma atração. Daí Kierkegaard dizer ser a angústia ambígua e que tem uma importância não só filosófica como também teológica. A angústia torna-se uma categoria fundamental para Kierkegaard expor a natureza do pecado.

Em O conceito de angústia, - kierkegaard redefine a angústia como sendo: " uma determinação do espírito sonhador (...) é a realidade da liberdade como puro possível" (Kierkegaard, 1968, p. 45). Kierkegaard começa sua analise do conceito de angustia a partir do mito da queda de Adão e Eva. 
De acordo com Kierkegaard eles são colocados diante da possibilidade de escolher. Com a queda eles entram na existência, ou seja, eles começam a existir, no sentido de que a existência humana implica decisão, escolha, não são mais determinados pela natureza. Enquanto viviam no paraíso eles não se conheciam a possibilidade da escolha. Assim, é a partir da queda que a angustia instaura sua morada na existência, torna-se presente no ser humano e o homem será desde então um ser angustiado.

Ao lado da angustia, Kierkegaard coloca também outra categoria humana, que é o desespero. $\mathrm{O}$ desespero humano está ligado ao fracasso da condição, do absurdo, do paradoxo, ou seja, o homem é finito e ao mesmo tempo deseja o infinito, que transcender a essa condição de finitude. De acordo com a filosofia kierkegaardiana, o desespero surge quando o espírito quer a síntese de finito (matéria) e infinito (espírito) para surgir o "EU EXISTENCIAL”.

Conforme nos referimos acima, o problema da angustia torna-se central dentro do existencialismo, corrente filosófica iniciada por Kierkegaard. Assim, vamos encontrar a discussão deste tema nos outros filósofos existencialistas como Heidegger, Karl Jaspers e Sartre.
Para o alemão Martin Heidegger, a angústia é um sentimento diferente do medo; o medo implica geralmente um objeto determinado. Como afirma Heidegger em Ser e Tempo, "na angustia a pre-sença se dispõe frente ao nada da possível impossibilidade de sua existência" (HEIDEGGER, 1998) A angústia nunca anuncia o perigo, mas é provocado por um existente determinado. Assim, o angustiado não sabe de onde lhe vem a angústia. $\mathrm{O}$ que ele sabe é que ela não lhe vem de um objeto determinado. A angústia, é pois, o seu esta-no-mundo.

Ainda nesta Obra Ser e Tempo, afirma Heidegger a respeito da angústia:

O ser-para-a-morte é,
essencialmente, angústia. Isso é
testemunhado, de modo indubitável
embora "apenas" indireto, pelo ser-
para-amorte já caracterizado, no
momento em que a angústia se faz
temor covarde e, superando,
denuncia a covardia da angústia.
(HEIDEGGER, 1998, P. 50)

Desta forma, para Heidegger a angústia é um determinante existencial, e que a angústia se manifesta na cotidianidade do estar-no-mundo.

Karl Jaspers fala de dois tipos de angústia, uma "angustia empírica" e um "angustia existencial"; a angústia empírica tem um caráter psicológico e a angustia existencial 
se manifesta diante das situações limites como a culpa, a dor, a luta e a morte. Essas situações limites nos fazem ascender à transcendência.

O francês, Sartre diz que a angústia é a consciência especifica da liberdade. Diante da angústia o homem pode até ensaiar condutas de fuga, refugiar-se na crença, no determinismo, que o reintegra no ser. Mas não pode escapar da angústia. Ele pode oculta-la por momentos, mas não suprimila. Para Sartre o homem é angústia. Em uma belíssima passagem do seu livro "o existencialismo é um humanismo" ele escreve:

Em primeiro lugar, como devemos entender a angústia? $\mathrm{O}$ existencialista declara frequentemente que o homem é angústia. Tal afirmação significa o seguinte: o homem que se engaja e que se dá conta de ele não é apenas aquele que escolheu ser, mas também um legislador que escolhe simultaneamente a si mesmo e a humanidade inteira, não consegue escapar ao sentimento de sua total e profunda responsabilidade. É fato que muitas pessoas não sentem ansiedade, porém nós estamos convictos de que essas pessoas mascaram a ansiedade perante si mesmas, evitam encará-la; certamente muitos pensam que, ao agir, estão apenas engajando a si próprios e, quando se lhes pergunta: mas se todos fizessem o mesmo?, eles encolhem os ombros e respondem: nem todos fazem o mesmo. (SARTRE, 1987.P. 7) suas ações e escolhas, e é para Sartre esta possibilidade da escolha que nos revela a angústia. Não há como fugir dessa responsabilidade, nem mesmo quando não escolho, eu estou escolhendo não escolher.

Voltando ao pensamento de Kierkegaard, podemos afirmar que o problema da angustia perpassa toda a sua filosofia. Isto pode perceber em suas obras como "o conceito de angúsita, "o desespero humano" temor e tremor".

\section{A angústia para Kierkegaard é a} possibilidade de liberdade. Kierkegaard afirma que a angústia pode ser de dois tipos objetiva e subjetiva. Em O conceito de angústia; ele escreve assim:

\begin{tabular}{|c|}
\hline 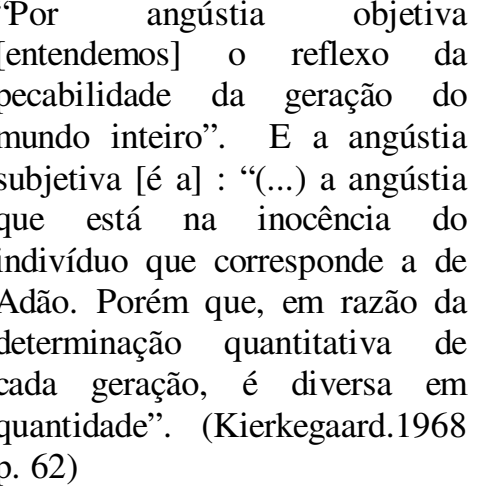 \\
\hline
\end{tabular}

Vimos assim, que em Heidegger, Sartre e K. Jaspers o conceito de angústia tem características comuns, descrita resumidamente como algo inerente a existência humana.

Para Sartre a angústia está relacionada a essa total responsabilidade do sujeito sobre 


\section{A origem da angústia}

O home é o único ser que jamais consente se o que é; assim, ele está sempre buscando, ele é desejo, de busca. Somente ele sente profundamente o vazio de sua existência. Não aceita a sua existência como simples trajetória entre o nascer e o morrer. E é justamente neste ponto que repousa a sua grandeza, mas por outro lado funda-se aqui o problema que terá que enfrentar por toda a vida. Sua grandeza por que sendo finito (matéria) e infinito (espirito), "porque o EU é uma síntese de finito que delimita e de infinito que ilimita” (KIERKEGAARD, 1988, P. 208) ele tem que administrar esta tensão entre estes dois elementos para construir formas de dar sentido à sua existência, para que esta não se reduza a um simples "estar no mundo". O problema é que esta situação faz do homem um "eterno viajante" em busca de sentido para sua vida, para construir uma existência autêntica.

Segundo Kierkegaard o homem em um primeiro momento é pura possibilidade, neste estagio, o que existe é o nada. E afirma Kierkegaard em $\mathrm{O}$ Conceito de Angúsita: produz, porém este nada? Este nada dá nascimento à angustia. (Kierkegaard. 1968. P. 45)
Kierkegaard, escreve que quando Adão e Eva ainda no paraíso, no estado de inocência foram advertidos para não comerem do "fruto de uma árvore" do conhecimento eles não podiam entender do que se tratava, porém, esta advertência, ou melhor a proibição é que desperta neles a possibilidade de liberdade. Neste momento eles são repelidos e ao mesmo tempo atraídos por esta situação. Eles estão agora diante da possibilidade de fazerem uma escolha, a proibição desperta-lhes o desejo de ser como "Deus", estão diante de uma possibilidade, mas esta possibilidade também lhes causa vertigem, eles sentem no dizer de Kierkegaard, uma antipatia simpatizante uma simpatia antipatizante. É a proibição que desperta neles o desejo de conhecer, ainda na obra citada acima, Kierkegaard reitera:
Porém existe, ao mesmo tempo, outra coisa que, entretanto, não é perturbação nem luta, porque não existe nada com que lutar. $\mathrm{O}$ que existe então? Nada. Que efeito
A proibição deixa inquieto Adão, porque nele desperta a possibilidade da liberdade. $\mathrm{O}$ que se ofertava à inocência como um nada da angústia adentrou-o e conserva ainda aqui um nada: a aflitiva possibilidade de poder. Com respeito ao que pode, não tem nenhuma ideia. (...) existe em Adão somente a possibilidade de poder, como uma forma superior de ignorância, como expressão elevada da angústia, visto que, a este nível mais alto, a angústia existe e não existe, Adão tem amor e foge dela. (Kierkegaard, 1968. 48) 
Vimos até aqui o conceito de angustia, e que ela é própria do ser humano, assim, na concepção do filosofo Dinamarquês Kierkegaard, a angústia não é expressão de uma patologia, mas uma dinâmica da própria existência. É uma categoria fundamental da existência humana.

\section{O sentido existencial da Angústia.}

Falar de sentido existencial da angústia é enfatizar a centralidade da questão, na perspectiva kierkegaardiana. E de certa forma chamar a atenção para o fato de que ela é inerente à existência humana e não se apresenta como uma neurose. Desta forma, a angústia no sentido kierkegaardiano não pode ser equiparada a inquietação, ansiedade ao temor ou desespero. Estas categorias são todas vivenciadas pelo ser humano, mas ainda não representa aquilo que é mais fundante e profundo na existência humana, que é a angústia. A angústia abordada por Kierkegaard é a angústia existencial que não é momentânea nem tem um objeto específico.

A angústia não tem um objeto definido, é algo vago, indeterminado. Daí também ter ela outra característica que é de não ser passageira, ela acompanhará o homem enquanto ele viver. Portanto, não há outro caminho a não ser enfrentá-la, experimentá-la, fugir não é de forma alguma a solução, afirma Kierkegaard. Neste sentido não adianta desangustiar os homens, mas ensiná-los a vivenciar a sua angústia. Assim o homem será tanto mais humano quanto mais profunda for a sua angústia no sentido de experiência existencial. E neste sentido Kierkegaard não quer apontar uma saída, mas fazer com que o ser humano aprenda com a angústia.

Nestes termos a angústia não tem, na perspectiva kierkegaardiana um caráter negativo. Kierkegaard enfatiza a centralidade da angústia justamente para dizer que ela é uma categoria fundamental para que o homem adquira sua autonomia e liberdade. conforme ele escreve em "O Conceito de Angústia”: “(...) assumindo tal aspecto (...) a angústia transmuda para ele, em uma criada invisível que, ainda sem querer, o leva aonde pretende ir" (Kierkegaard. 1968, p.160) ou seja, ela tem um sentido positivo, como veremos adiante.

\section{O sentido positivo da angustia}

Kierkegaard em, o conceito de angústia, e de algum modo em obras como Temor e tremor e também o Desespero Humano descreve o sentido positivo da angústia, ou pelo menos, nos dá pistas de como a angústia quando assumida de forma correta tem um valor extremamente positivo para a 
constituição da existência autêntica. Em todas estas obras aparece muito claro, o pensamento do filósofo e sua tentativa de mostrar caminhos ao homem para que ele assuma, na sua vida, valores que estejam acima do imediato, do aqui e agora.

Em Temor e tremor, Kierkegaard chama atenção para o cavaleiro da fé, que é diferente do herói. Segundo ele, não obstante todas as glórias conquistadas pelo herói, estas ainda não se aproximam daquilo que é o ideal de homem, o cavaleiro da fé, que nesta obra de Kierkegaard é representado por Abraão. Soa estranho quando Abraão decide oferecer seu único filho, o filho da promessa em sacrifício a Deus. Aqui, não fala mais a moralidade, pois Abraão naquele momento está na instância da fé, Ele vive a angústia mas silencia, descreve Kierkegaard, por isso ele afirma que "a fé é esse paradoxo, e o indivíduo não pode de forma alguma fazer-se compreender por ninguém” (Kierkegaard. 1959, p.126)

Kierkegaard, portanto nos ensina que só aqueles que assumem esta angústia de forma positiva, é capaz de dar um salto qualitativo. Assim, fazer-se discípulo da angústia é fundamental para que o individuo se torne verdadeiramente homem. Neste sentido Ernest Becker comenta em seu livro a Negação da Morte:
Kierkegaard tinha uma formula própria para o que significa ser um homem. Ele a expôs naquelas páginas admiráveis nas quais descreve o que chama de "o cavaleiro da fé". Essa figura é o homem que vive na fé, que entregou o significado da vida ao seu criador e que vive concentrado nas energias do seu Deus. Aceita sem reclamar o que quer que aconteça nessa dimensão visível, vive a vida como um dever, enfrenta a morte sem receio" ( Becker. 1995. P 251)

Colocados nestes termos, à primeira vista parece que a proposta é de capitulação ${ }^{2}$ diante de Deus. Uma entrega desonesta e descompromissada. Mas não é esta a proposta de Kierkegaard. O importante é que o homem assuma sua vida com consciência desta dimensão, que ele existe para realizar-se além da imediatidade que a vida propõe e que as vezes parece até mais fácil. Nesta tarefa a angústia terá um papel fundamental, ela será o caminho que o individuo deverá trilhar para alcançar este objetivo. Neste sentido ele terá um papel não só positivo, mas fundamental. Porém, o homem atual vive cercado de possibilidades, tem ao seu redor uma gama de facilidades, e a todo instante é tentado a tomar o caminho mais fácil. Luiz Cláudio Batista, em um artigo intitulado "A angústia kierkegaardiana como pressuposto da angústia do homem contemporâneo descreve assim a situação do homem em nossos dias:

\footnotetext{
${ }^{2}$ Capitulação: entrega, resignação.
} 
Feliz por ter à mão as facilidades possíveis, feliz pois consegue jogar com a máquina e com isso sua vida torna-se mais cômoda. Qualquer momento infeliz é logo compensado por uma aquisição no primeiro shopping da esquina. O paradoxo talvez esteja em encontrar um homem triste, indiferente, isolado". (BATISTA, 1997.P. 311)

Em outras palavras poderíamos dizer que o homem moderno tem, de certa forma, medo de enfrentara a angústia, por isto vive esta situação de constante busca de meios para não confrontar-se com ela. Por isso ele prefere perder-se na massa a encontrar-se só, como arquiteto de sua vida, prefere viver em função da opinião, onde não precisa responder muitas perguntas, a viver a sua individualidade. Isto tem seus reflexos diretos na vida do próprio homem, pois esta forma de não assumir a sua angústia, de querer a todo custo evita-la, volta contra ele sob a forma de neuroses. Delfim Santos, comenta assim esse medo da angústia em que vive o homem atual.

(...) a nossa época pode caracterizar-se pelo medo da angústia. Nunca este medo se revelou com tal intensidade, e também nunca os estados patológicos derivados do medo foram tão frequentes. (...) em época mecanizada sob forma burocrática, em que a pretensa autenticidade e competência são garantidas pela convenção e pela rotina, em que a angústia não tem onde reclinar a cabeça, não é de se estranhar que a diagnose leve a conclusão de que o signo do nosso tempo, em todos os planos se caracteriza pela predominância da reação neurótica". (SANTOS, 1982.p. 164).

Este medo da angústia leva o homem a uma situação de confinamento, e o faz erguer barreiras de todo tipo contra a angústia. Este porém, não é o caminho proposto por Kierkegaard, ele propõe justamente o contrário, que o homem aceite sua condição de finitude, mas que carregue em si o desejo de infinito, que se torne discípulo da angústia. Pois somente assim a angústia assumirá para ele um sentido positivo, e o ajudará a dar o salto qualitativo. Salto possível somente ao homem que não aceita a simples transitoriedade da vida. E isto é imprescindível a aceitação da angústia como parte da existência. A angústia terá assim um sentido positivo e libertador, transformando-se em expressão de maturidade e liberdade. Ajudando o individuo a trilhar um novo caminho, o caminho da existência autêntica, segundo Kierkegaard.

\section{A existência autêntica}

Conforme refere acima, o homem é o único ser que pensa a sua vida, que projeta, que preocupa, ou seja, somente ele tem consciência da sua existência, das suas limitações e finitude. Vive não só o seu momento presente mas é capaz de projetar- 
se no futuro e recordar o passado. Sendo o homem consciência, ele aspira ao transcendente; não se satisfaz com o simples existir. Sabe que apesar de sua finitude traz dentro de si a chama de eternidade.

O homem é. Segunda a concepção de Kierkegaard, uma síntese de finito e infinto, e por ele ser esta síntese ele quer alçar vôos mais altos. Traz em sim a marca transcendental, não se conforma com a sua finitude, busca rebelar-se contra a sua condição de ser apenas mais um individuo no meio da multidão. Somente o confronto com a angustia vai permitir ao homem o salto para aquele modo de vida que Kierkegaard descreveu como sendo a existência autêntica.

Fazer esta caminhada pode custar muito, este é o motivo pelo qual nem todos estão dispostos a fazer. Esta caminhada será também escolha, um proposito, e só aquele que realmente quer chegar lá é que se põe a caminhar. Este trabalho, é fruto do esforço de cada um, conforme afirma Nietzsche, somente você poderá construir as pontes que precisa para atravessar o rio da existência, só você e mais ninguém. E Kierkegaard, diz isto de outra maneira em Temor e Tremor: "ora, consiste o segredfo da vida em que cada um deve cozer a sua própria camisa e coisa curiosa, o homem pode fazê-lo tão perfeitamente quanto uma mulher" (Kierkegaard, 1959, p. 81). Cada pessoa deve assumir o leme, não há como confiar essa tarefa a outrem. Isto fica bem claro em Kierkegaard e nos outros existencialistas, delegam ao homem o destino e deste ele não pode se esquivar se quiser construir uma existência autentica, se quiser elevar-se acima da massa.

Teria sentido falar de existência autêntica hoje, onde cada vez mais o sujeito é absorvido pela multidão, pela massa? Todos podem atingir essa existência autêntica ou apenas alguns privilegiados? Estas são questões que surgem quando vemos a proposta de Kierkegaard para a construção da existência autentica. Em princípio parece um caminho difícil, pois aqueles que se propõe a realiza-lo não está do lado da maioria, por outro lado este passo é libertador, pois segundo Kierkegaard propiciaria a conquista da liberdade e da autonomia. Mas, é justamente isto que muitos temem. Não dar este passo é muito tentador. Muitos preferem perder-se na multidão, viver das convenções sociais, adotar como modo de vida o stablishmant social, onde se sentirão seguros; ou como escreveu Erich Fromm, em Ter ou Ser:

\footnotetext{
Não nos movemos para frente, permanecemos onde estamos, regressamos, em outras palavras,
} 
confiamos no que temos, é muito tentador, visto que o que temos, nós conhecemos; podemos agarrá-lo, sentimo-nos seguros nele. Receamos, e portanto evitamos, dar um passo ao desconhecido, ao incerto; por que na verdade, embora passo a passo possa não parecer arriscado depois de dado, antes dele tudo parece perigoso, e daí temerário empreendê-lo. Somente o velho, o experimentado, o seguro, ou quem assim pareça. Todo passo novo traz em si o risco do fracasso, e esta é uma das razões pelas quais tanto se teme a liberdade. (FROMM, 1987,p. 114).

O que Fromm descreve no trecho acima é o que anteriormente chamamos de medo da angústia, o que é na verdade plausível e profundamente humano, pois nem todos querem se arricar, deixar o seu mundo seguro, protegido para dar um passo no desconhecido. Por mais que este seja nobre e grandioso, ele é temível. Mas como ensinou Kierkegaard, este passo depende de sua escolha, você pode ou não ir adiante. Assumir isto tem o seu preço, e também a sua recompensa, que é a liberdade. Não submeter a opinião da massa e construir uma existência autêntica.

A maioria dos homens, contudo, vivem no estágio da existência inautêntica. Este é o modo fácil de viver que não exige muito esforço ou sacrifício. A nossa época é um grande convite a continuarmos neste estado de vida. Somos a cada instante chamados a mergulhar na massa, a sermos heróis, a agradar os outros. A este respeito escreveu Ernest Becker em seu livro, A negação da Morte:

\begin{abstract}
O sistema social de heróis em que nascemos traça trilhas para o nosso heroísmo, trilhas com as quais nos conformamos, às quais nos moldamos para que possamos agradar aos outros, tornamo-nos aquilo que os outros esperam que sejamos. E em vez de trabalhar o nosso segredo interior, vamos aos poucos cobrindo-o e esquecendo-o, enquanto nos tornamos homens puramente exteriores, jogando com sucesso o padronizado jogo dos heróis. (BECKER, 1995, p. 91)
\end{abstract}

A existência inautêntica caracteriza-se pela subordinação do "EU” ao "TU”, vive-se em função da opinião, da loquacidade e da curiosidade, e é neste mundo fácil que vive a maior parte dos homens. Ao lado dos que vivem desta maneira estão aqueles que tentam construir o seu "EU" e alcançando maturidade enfrentam sozinhos os desafios, não se preocupam em justificar suas ações - modo típico dos que vivem na inautenticidade - o homem que opta pela existência autêntica não depende da opinião dos outros, não vive em função das convenções e não espera elogios.

\section{Kierkegaard e o nosso tempo}

A reflexão filosófica de Kierkegaard é fruto de sua própria luta interior, a luta de quem sentiu profundamente a dramaticidade da vida e que com coragem 
enfrentou esta luta. E como escreveu Ernest Becker,

Kierkegaard nada tinha de cientista desinteressado. Ele deu uma descrição psicológica por que teve um vislumbre da liberdade para o homem. Era um teórico da personalidade aberta, da possibilidade humana. (BECKER, 1995.p.94)

Podemos observar isto quando ele analisa categorias como a angústia, o desespero, o pecado, a fé e a solidão. Levanta a sua voz de cristão "revoltado", contra uma fé sem angústia e sem risco. Contra aqueles que se deixavam levar pelas aparências, submetendo-se à massa. Protesta contra a igreja institucionalizante da Dinamarca, para ele a fé é paradoxo, é absurdo, é risco, é coragem de estar só diante do OUTRO, que é Deus.

Outro ponto de encontro entre Kierkegaard e os nossos dias, e já naquele tempo a sua preocupação com a existência, em função das questões que surgem em nossa época. E novamente o problema da existência volta a ser uma preocupação para todos. Ou como escreveu Miguel Reale:

Kierkegaard pode ser visto como um rebelado, para quem o problema central é o da existência e do ser particular existente, e não do ser que previamente indaga das possibilidades do conhecimento (Kant) ou deixa de fazer tal indagação, por ser o pensamento a realidade mesma (Hegel).
Compreende por esse aspecto a contemporaneidade do pensador dinamarquês, quando ressurgem novas preocupações pela problemática não só da existência como do ser. (REALE, 1956, p. 186-187)

Podemos ver nestas palavras de Miguel Reale, que a grande preocupação de Kierkegaard era com o homem concreto. Ele levanta a voz contra o sistema idealista de Hegel, compreendendo que nenhum sistema pode abarcar todas as realidade humanas. $\mathrm{O}$ homem não se reduz apenas ao racional. Hoje temos consciência de que apesar de todo o avanço das ciências e o desenvolvimento da racionalidade, continua ainda aberto à complexidade, daí a importância e atualidade do seu pensamento.

O homem pós moderno, marcado pela complexidade, vive mais que nunca uma crise de identidade, as novas técnicas de comunicação as facilidades da vida moderna fizeram com que surgissem diversos problemas para o sujeito contemporâneo. A cada instante recebemos um volume enorme de informações, diante desse mar de novidades homem não tem tempo de aprofundar nas experiências, vive-se de aparências.

Daí que pode-se afirmar que o homem pós moderno vive a perplexidade ante tantas possibilidades. Essa crise se refere a crise 
de paradigmas da ciência da religião e da própria racionalidade. Postulados como redentores do homem e que não foram suficientes na modernidade e pós modernidade. E apesar de todos os avanços nas ciências e em todos os conhecimentos o homem continua perdido, como escreve Heidegger:

Nenhuma época da história sabe tanto acerca do homem como a nossa. Nenhuma época expôs o seu saber a respeito do homem de uma maneira tão penetrante e fascinante como a nossa. Nunca o homem tornou-se tão problemático como no nosso tempo. (Heidegger, apud DelfimSantos, 1982. P.154)

A proposta de Kierkegaard, era a de assumir a angústia como um passo imprescindível para construir uma existência autêntica. A proposta de Kierkegaard era assumir a angústia no salto para a fé, este salto compreendido como adesão madura ao cristianismo. $\mathrm{O}$ homem chegaria a este estágio após passar pelo estágio estético e ético. Assim, somente tendo chegado ao estagio religioso o homem estaria em condições de assumir sua solidão diante de Deus. Assumindo assim a sua finitude frente ao desejo de infinito.

\section{Considerações finais}

O pensamento de kierkegaard neste início de terceiro milênio continua significativo e atual. Questões levantadas por Kierkegaard como a angústia, o desespero, o indivíduo e a fé que hoje podem soar estranhos aos ouvidos do homem pós-moderno mas que estes aspectos no dizer de Kierkegaard são inerentes ao ser humano e viver esta angústia existencial é fundamental para o ser humano construir aquilo que os existencialistas chamam de existência autêntica.

Um outro aspecto que nos permite pensar é o fato de que o homem contemporâneo sedento de orientações e sem paz interna e sem saber como conduzir a sua vida encontra no pensamento de Kierkegaard uma reflexão fundamental para construir a sua individualidade. Pode-se se ainda afirmar que o próprio Kierkegaard viveu um século antes, a crise dissociativa que agista o homem hoje. Neste momento em que cada vez mais o homem é convidado a fugir de si e submergir-se na massa, a viver conforme o "geral", o pensamento de Kierkegaard é para nós uma voz clamando para um retorno a uma existência mais autêntica, onde o homem seja capaz de confrontar-se consigo mesmo de forma madura e consciente. Percorrer este caminho é difícil, e é uma escolha pessoal, tarefa que deve ser assumida pelo indivíduo. Kierkegaard não constrói o caminho, nos dá algumas pistas. Cabe a cada ser humano decidir sobre seu caminho. Ele aponta as trilhas para 
construir uma verdadeira existência, a existência autêntica.

\section{Referencias}

BECKER, Ernest. A negação da morte. Rio de Janeiro: Record, 1995.

FROMM, Erich. Ter ou ser. Rio de Janeiro: Guanabara, 1987.

GIORDANI, Mário Curtis. Iniciação ao existencialismo. Petropolis: Vozes, 1997.

Kierkegaard, Soren. O conceito de Angústia. Lisboa: Hemus editora, 1968.

O Desespero humano. Col. Os pensadores. São pauloo: nova cultural, 1988.

SANTOS, Delfim. O sentido existencial da angustia. In: "obras completas" Vol. II, P. 153-165. Lisboa: Fundação Calouste Kulbekian, 1982. 